\title{
Laparoscopic ovarian drilling in clomiphene resistant polycystic ovarian syndrome: clinical response and outcome
}

\section{Jesmine Banu ${ }^{1 *}$, Shakeela Ishrat ${ }^{1}$, Farzana Deeba1, Chowdhury Faisal Alamgir ${ }^{2}$, Maliha Darmoni $^{2}$, Nurjahan Begum ${ }^{1}$, Shaheen Ara Anawary ${ }^{1}$}

\author{
${ }^{1}$ Department of Reproductive Endocrinology and Infertility BSMMU, Dhaka, Bangladesh \\ ${ }^{2}$ Mymensingh Medical College and Hospital, Mymensingh, Bangladesh
}

Received: 26 January 2021

Accepted: 06 August 2021

\author{
*Correspondence: \\ Dr. Jesmine Banu, \\ E-mail: kariul@hotmail.com
}

Copyright: (C) the author(s), publisher and licensee Medip Academy. This is an open-access article distributed under the terms of the Creative Commons Attribution Non-Commercial License, which permits unrestricted non-commercial use, distribution, and reproduction in any medium, provided the original work is properly cited.

\begin{abstract}
Background: Laparoscopic ovarian drilling (LOD) is an alternative method for ovulation induction in clomiphene citrate $(\mathrm{CC})$ resistant polycystic ovary syndrome (PCOS) patients instead of gonadotropins. Objective were to identify the changes in clinical and biochemical profiles and the ovulation and pregnancy rate following LOD in CC resistant PCOS patients.

Methods: It was an interventional study infertility unit, department of obstetrics and gynecology, Bangabandhu Sheikh Mujib medical university, Dhaka, between from July 2014 to June 2015. Changes of the above-mentioned parameters were recorded during follow up of patients after LOD. The information is collected and recorded in the preset questionnaire.

Results: The characteristics of study population were same before LOD and following LOD. Before LOD, infrequent menstruation was present in $83.3 \%$ patients whereas regular menstruation was found in $58.3 \%$ patients after 6 months following LOD. Endometrial thickness $\leq 8$ was found in $100.0 \%$ in before LOD and endometrial thickness $>8$ was found in $70.0 \%$ after 6 month following LOD. Ovulation was found in $25.0 \%$ in after 3-month LOD and was found in $70.0 \%$ after 6 months following LOD. Pregnancy was found in 20.0\% after 3 months following LOD and 50.0\% in after 6 months following LOD. Ovulation and pregnancy outcome was significantly higher in after 6 months following LOD. Conclusions: LOD produces long-term improvement in menstrual regularity and reproductive performance. A sustained improvement observed in acne and BMI. Ovulation and pregnancy were found in $70 \%$ and $50.0 \%$ respectively after 6 months following LOD.
\end{abstract}

Keywords: Laparoscopic, Ovarian drilling, Clomiphene resistant, PCOS

\section{INTRODUCTION}

Polycystic ovarian syndrome (PCOS) is the most common endocrine disorder affecting 5-10\% of women of reproductive age 1 but the prevalence of PCOS among the infertile women are $15 \%$ to $20 \%$, accounting for at least $75 \%$ of PCOS presenting with anovulatory infertility. ${ }^{1}$ It is characterized by a heterogeneous group of disorders that occur in varied combinations including: acne, hirsutism, oligomenorrhea or amenorrhea and elevated body mass index (BMI), biochemical (elevated circulating androgens and/or LH and evidence of insulin resistance) and/or ultrasound features of polycystic ovaries (increased ovarian volume $>10 \mathrm{ml}$ and/or number of small follicles $>12 .^{2}$ Although the underlying pathophysiology of PCOS remain uncertain, current evidence suggests that ovarian hyper secretion of androgen is the primary disorder in PCOS. $^{3}$ The diagnosis of PCOS was based on the following criteria appointed by Rotterdam criteria 2003, concluding that diagnosis of PCOS should be based on at 
least two out of three major criteria 1) Oligo/anovulation 2) Clinical or biochemical sign of hyperandrogenism and 3) Polycystic ovaries and also excluded other androgen excess disorder. ${ }^{4}$ The 2006 androgen excess (AE) PCOS society criteria allowed that PCOS could be considered a sign of ovarian dysfunction, but again emphasized that PCOS is characterized first and foremost by hyperandrogenism including women with either oligo/amenorrhea or PCOS but excluding those having neither hyperandrogenemia nor hirsutism. Most women of PCOS with anovulation are treated with $\mathrm{CC}$ to induce ovulation but $10-20 \%$ will remain resistant. Insulin resistance with compensatory hyperinsulinemia is a prominent feature of the syndrome and appears to have a patho-physiological role in the hyperandrogenism of the disorder. Hyperinsulinemia results in increased ovarian androgen biosynthesis and decreased sex-hormonebinding globulin synthesis from the liver, leading to increased bioavailability of free androgen. The excess in local ovarian androgen augmented by hyperinsulinemia causes premature follicular atresia and anovulation. The excess in local ovarian androgen augmented by hyperinsulinemia causes premature follicular atresia and anovulation.

\section{IN SU LIN RESISTANCE}

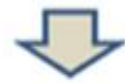

HYPERINSU LINEM IA

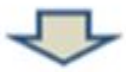

\section{THECA CELL PROLIFERATION}

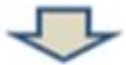

\section{HYPERANDRO GENISM}

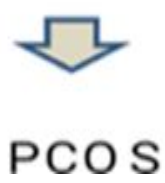

Figure 1: Flow chart.

LOD has been widely used to induce ovulation in PCOS women who are CC resistant. In this study we shall identify the various clinical, biochemical, and ultrasonography factors that are affected by LOD and clinical response to LOD in a larger series of PCOS patients. We were able to report the beneficial effects of LOD in the responders. Dwan et al and Liguori et al have reported that beneficial effects were found after electrocauterization whereas Amer et al have reported that there was an improvement in hirsutism in $25 \%$ of patients. ${ }^{5-7}$

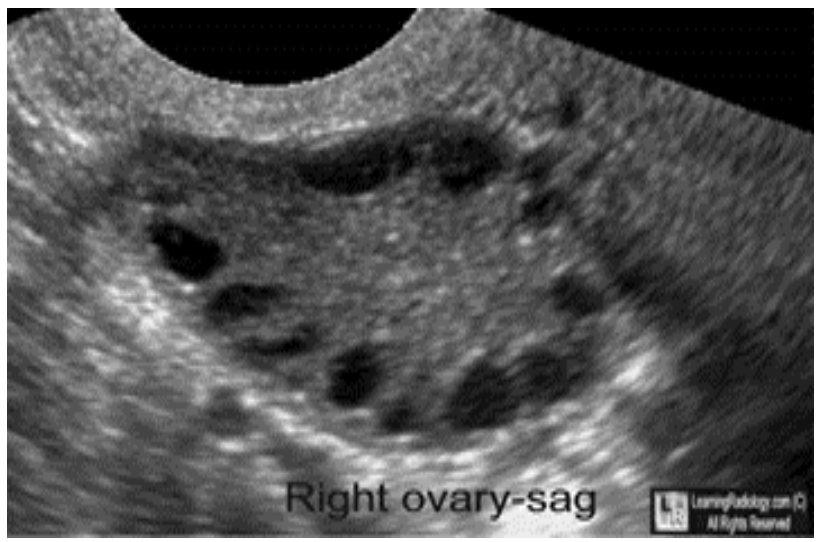

Figure 2

The $40 \%$ in acne in cases treated with LOD. Lemieux has reported that there was a fall of testosterone by $48 \% .^{8}$ Felemban et al has reported a post operative adhesion rate of $27 \% .9^{9}$ Tulandi et al measured ovarian volume by $3 \mathrm{D}$ USG in CC resistant PCOS patients undergoing LOD. ${ }^{10} \mathrm{In}$ this study we shall identify the various clinical, biochemical, and ultrasonography factors that are affected by LOD and clinical response to LOD in a larger series of PCOS patients. We were able to report the beneficial effects of LOD in the responders. In this study we shall identify the various clinical, biochemical, and ultrasonography factors that are affected by LOD and clinical response to LOD in a larger series of PCOS patients. We were able to report the beneficial effects of LOD in the responders.

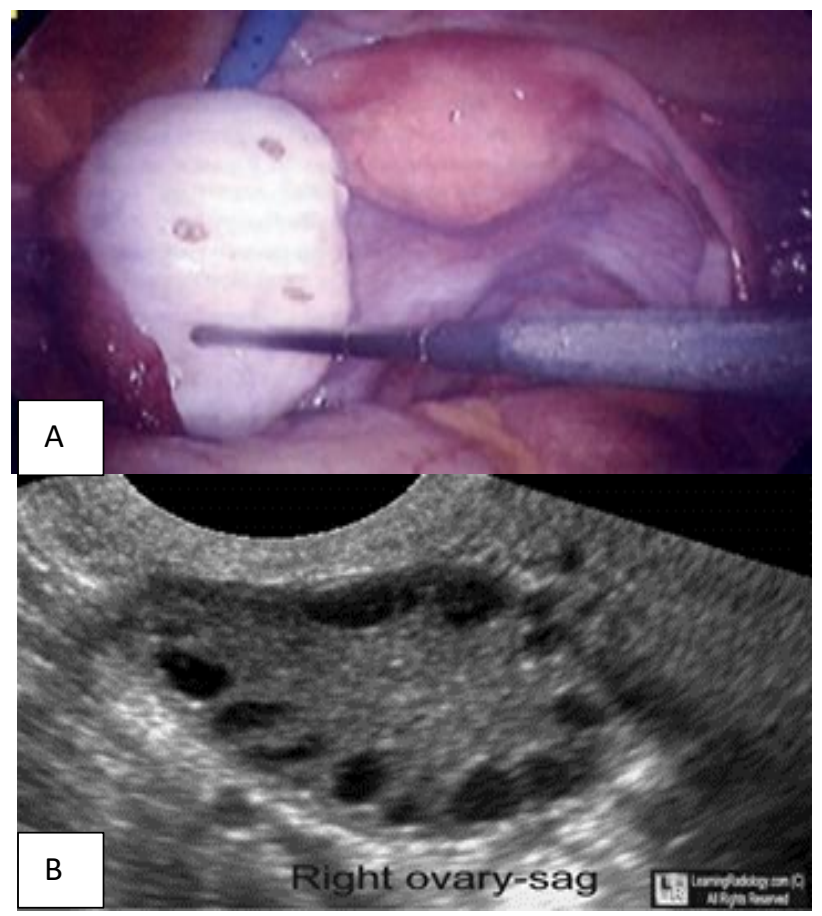

Figure 3: (A and B) Ovary-sag. 
The changes in clinical parameters (Acne, BMI, menstrual cycle patterns) following LOD were recorded every monthly for 6 months. The changes of biochemical parameters (day 2 serum LH and serum FSH, serum testosterone, OGTT and fasting insulin), were recorded after 6 months following LOD. The changes of sonographic parameters (ovarian volume, follicular development, endometrial thickness and ovulation) were done monthly for 6 cycles. Ovulation is diagnosed by follicular collapse and decrease follicular size, collection of fluid in pouch of Douglas, and absence of triple layer in the endometrium. Pregnancy was diagnosed by quantitative estimation of serum $\beta$ hCG. Biochemical pregnancy (Serum $\beta \mathrm{hCG}>5 \mathrm{IU} / \mathrm{ml}$ ) 2 weeks after sonographic evidence of ovulation. Pregnancy was recorded following missed period by serum $\beta$ hCG and presence of intrauterine sac by USG total follow up was done. After 3 months as well as 6 months of the following LOD.

\section{METHODS}

This is an interventional study which was carried out in the infertility OPD, department of obstetrics and gynecology, Bangabandhu Sheikh Mujib medical university, Dhaka between July 2014 to June 2015. Total of 66 patients were included in this study fulfilled inclusion criteria. However, 6 patients had to be excluded from the study due to drop out. In this study, complete history, physical examination, basal level of day 2 serum FSH and LH, and testosterone hormones OGTT and fasting insulin level were done before LOD. The characteristics of the study population (cc resistant PCOS patients) before LOD and after LOD were same and study were done on same group of patients. They were evaluated for clinical and biochemical parameters and TVS findings. In this way, the study populations before LOD group were selected as control for the current study and it was a historical control. The changes in all the parameters were recorded following LOD group. In this way, they were selected as cases for the study. LOD-A specially designed diathermy probe using monopolar coagulating current at $40 \mathrm{~W}$ power setting, four to six punctures were made in each ovary. Depending on its size, $4 \mathrm{~mm}$ in depth and the duration of each penetration was 4 seconds. Following LOD, changes of clinical, biochemical and sonographic parameters and the outcome of LOD in terms of ovulation and pregnancy were recorded.

\section{RESULTS}

Total 66 CC resistant PCOS patients were included in this study with maintaining inclusion criteria. However, among them, six were excluded from the study due to drop out. Finally, 60 cases were included in this study. In this study, a complete history, physical examination was done. Basal level of day 2 serum FSH and LH, and serum testosterone OGTT and fasting insulin level were recorded. All these clinical, biochemical and radiological parameters were repeated in the follow up period to identify the changes in clinical and biochemical profile and the ovulation and pregnancy rate following LOD. LOD has been widely used to induce ovulation in PCOS women who are CC resistant. It was observed that regular menstrual cycle was found in $16.7 \%$ patients before LOD and was found in $58.3 \%$ patients after 6 months following LOD. Acne was found in $36.7 \%$ patients before LOD and was found in $21.7 \%$ patients after 6 months following LOD. BMI $\left(>25 \mathrm{~kg} / \mathrm{m}^{2}\right)$ was found in $71.7 \%$ patients before LOD and was found in $50.0 \%$ patients 6 month following LOD. Mean LH level was found in $17.6 \pm 4.6 \mathrm{mIU} / \mathrm{min}$ before LOD and was found in $9.0 \pm 0.6 \mathrm{mIU} / \mathrm{ml}$ after 6 month following laparoscopic ovarian drilling. Mean testosterone was found in $31.1 \pm 12.7 \mathrm{ngm} / \mathrm{dl}$ patients before LOD and was found in $16.6 \pm 0.8 \mathrm{ngm} / \mathrm{dl}$ after 6 months following LOD. Mean fasting insulin was found in $21.9 \pm 4.3 \mu \mathrm{U} / \mathrm{ml}$ before LOD and was found in $16.4 \pm 0.9 \mu \mathrm{U} / \mathrm{ml}$ after 6 month following LOD. Mean OGTT was found in $8.3 \pm 1.1$ $\mathrm{mmol} / \mathrm{L}$ in before LOD and was found in $7.3 \pm 0.3 \mathrm{mmol} / \mathrm{L}$ 6 month following LOD which were statistically significant $(\mathrm{p}<0.05)$ compare with before LOD and after 6 month following LOD.

Table 1: Clinical and biochemical parameter of the study populations following LOD, according to sample size, $(\mathrm{n}=60)$.

\begin{tabular}{|c|c|c|c|c|c|}
\hline $\begin{array}{l}\text { Clinical and biochemical } \\
\text { parameters }\end{array}$ & Before LOD & Percent $(\%)$ & $\begin{array}{l}\text { After } 6 \text { months } \\
\text { LOD }\end{array}$ & Percent (\%) & P value \\
\hline Regular menstruation & 10 & 16.7 & 35 & 58.3 & 0.001 \\
\hline Acne & 22 & 36.7 & 13 & 21.7 & 0.004 \\
\hline BMI $\left(>25 \mathrm{~kg} / \mathrm{m}^{2}\right)$ & 43 & 71.7 & 30 & 50.0 & 0.001 \\
\hline
\end{tabular}

Table 2: Clinical and biochemical parameter of the study populations following LOD, according to mean \pm SD $(n=60)$.

\begin{tabular}{|c|c|c|c|}
\hline $\begin{array}{l}\text { Clinical and biochemical } \\
\text { parameters }\end{array}$ & Before LOD, mean \pm SD & $\begin{array}{l}\text { After } 6 \text { Month LOD, } \\
\text { mean } \pm \text { SD }\end{array}$ & $P$ value \\
\hline FSH level (mIU/ml) & $6.0 \pm 1.5$ & $5.9 \pm 0.6$ & \multirow{2}{*}{0.731} \\
\hline Range (min-max) & $3.1-8.0$ & $5.0-7.0$ & \\
\hline Luteinizing hormone (mIU/ml) & $17.6 \pm 4.6$ & $9.0 \pm 0.6$ & 0.001 \\
\hline
\end{tabular}




\begin{tabular}{|llll|}
\hline $\begin{array}{l}\text { Clinical and biochemical } \\
\text { parameters }\end{array}$ & Before LOD, mean \pm SD & $\begin{array}{l}\text { After 6 Month LOD, } \\
\text { mean } \pm \text { SD }\end{array}$ & P value \\
\hline Range (min-max) & $10.3-25.0$ & $8.0-9.9$ & 0.001 \\
\hline Testosterone (ngm/dl) & $31.1 \pm 12.7$ & $16.6 \pm 0.8$ & 0.001 \\
\hline Range (min-max) & $10.1-54.9$ & $15.1-18.0$ & 0.001 \\
\hline Fasting insulin pu/ml & $21.9 \pm 4.3$ & $16.4 \pm 0.9$ & 0.001 \\
\hline Range (min-max) & $15.5-29.8$ & $15.0-18.0$ & $7.3 \pm 0.3$ \\
\hline OGTT (mmol/L) & $8.3 \pm 1.1$ & $6.8-7.8$ & \\
\hline Range (min-max) & $6.8-9.9$ & & \\
\hline
\end{tabular}

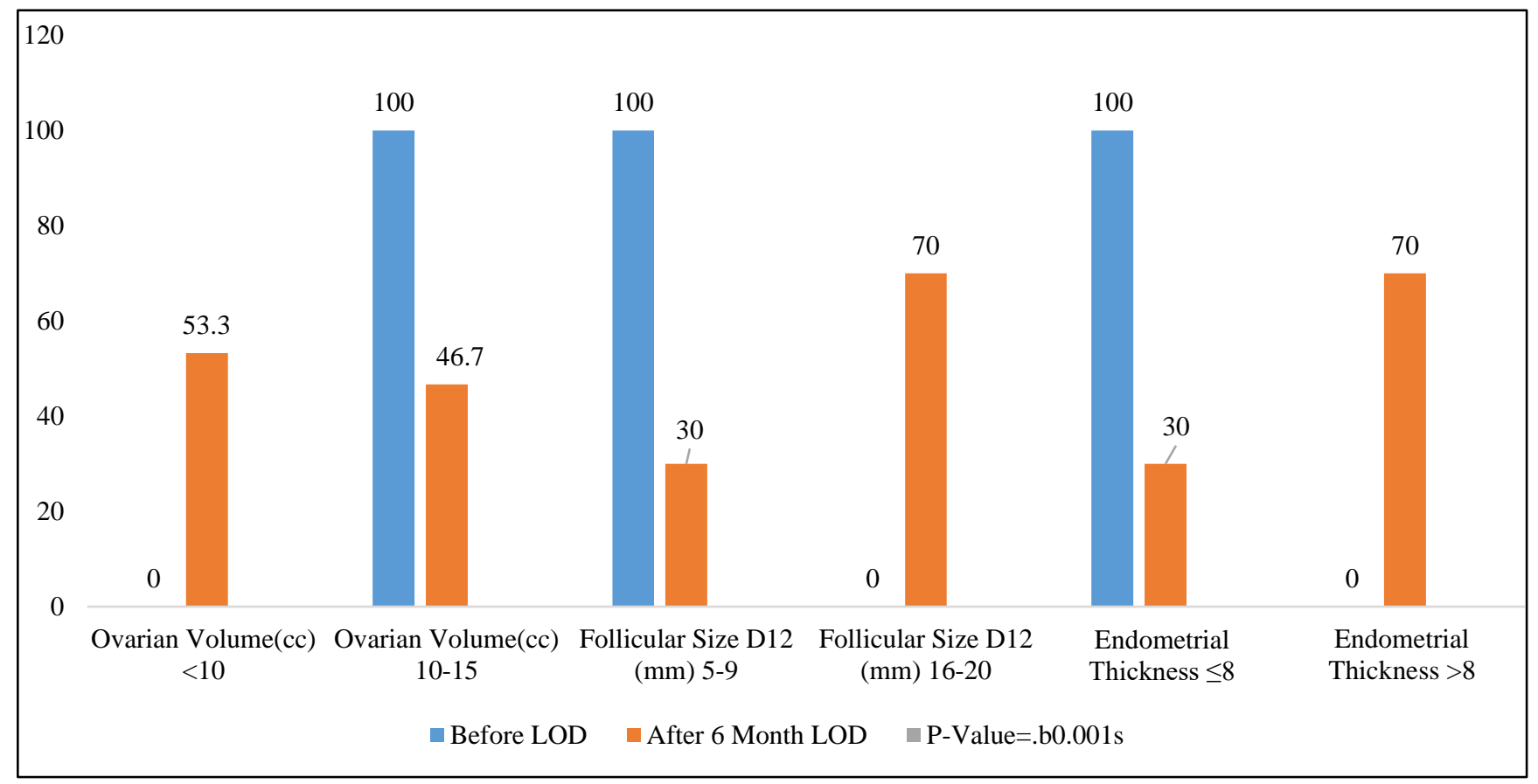

Figure 4: Ovulatory response according to TVS finding following LOD, $(n=60)$.

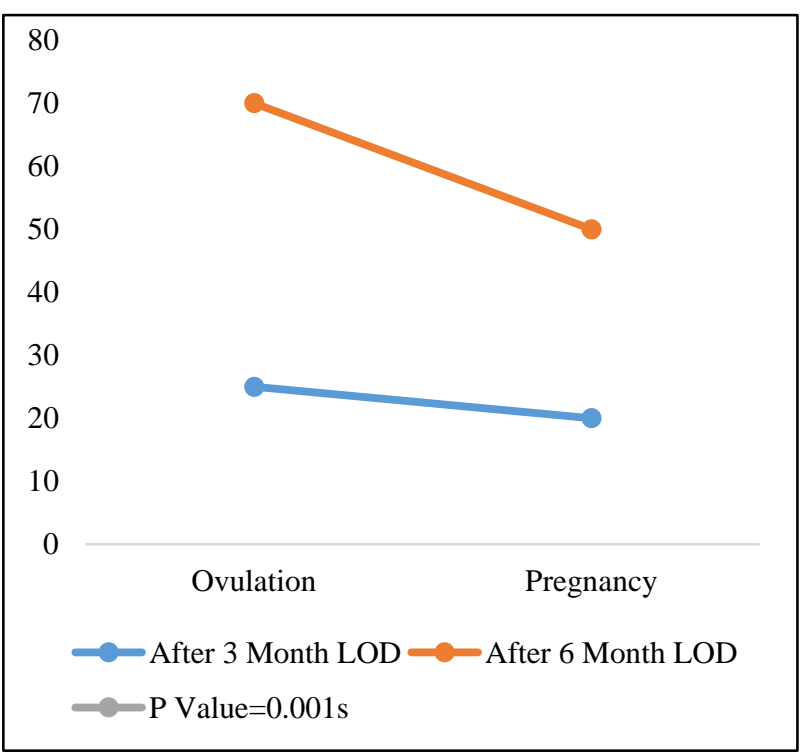

Figure 5: Distribution of the study population according to outcome with different follow up of, $(n=60)$.
Clinical parameters were recorded monthly for 6 months. It was found that there was a gradual improvement of menstruation. Regular menstruation was found in $1^{\text {st }}$ month, $3^{\text {rd }}$ month, $6^{\text {th }}$ month following LOD $25 \%, 41.7 \%$, $58.3 \%$ respectively. $\mathrm{P}$ value reached from McNemar test Sonographic parameters were recorded monthly for 6 months. It was found that there was a gradual improvement of anovulation. Ovarian volume $<10 \mathrm{cc}$ was found in $1^{\text {st }}$ month, $3^{\text {rd }}$ month, and $6^{\text {th }}$ month following LOD $13.3 \%$, $16.7 \%$, and $53.3 \%$ respectively which are not shown in the Table. Day 12 follicular size of $16-20 \mathrm{~mm}$ was found in $1^{\text {st }}$ month, $3^{\text {rd }}$ month, and $6^{\text {th }}$ month following LOD $8.4 \%$, $16.7 \%$, and $70 \%$ respectively which are not shown in the table. Endometrial thickness $>8 \mathrm{~mm}$ was found in in $40 \%$, $46.7 \%$, and $70 \%$ respectively which $\mathrm{Hb}$ are not show in the $1^{\text {st }}$ month, $3^{\text {rd }}$ month, and $6^{\text {th }}$ month following laparoscopic ovarian drilling Table. It was observed that ovarian volume of $10-15 \mathrm{cc}$ was found in $100.0 \%$ before LOD and ovarian volume $<10 \mathrm{cc}$ was found in $53.3 \%$ after 6 month following laparoscopic ovarian drilling, follicular size D12 5-9 $\mathrm{mm}$ was found in $100.0 \%$ before laparoscopic ovarian drilling and Follicular size D12 16-20 mm was found in 
$70.0 \%$ after 6month following laparoscopic ovarian drilling. Endometrial thickness, $\leq 8$ was found in $100.0 \%$ before laparoscopic ovarian drilling and endometrial thickness $>8$ was found in $70.0 \%$ after 6 month following laparoscopic ovarian drilling. It was observed that ovulation was found in $25.0 \%$ and $70.0 \%$ patients after 3 month and 6 months respectively following laparoscopic ovarian drilling. Ovulation rate was statistically significant $(\mathrm{p}<0.05)$ after 6 months following laparoscopic ovarian drilling. Pregnancy was found in $20.0 \%$ patients after 3 months following laparoscopic ovarian drilling and was found in $50.0 \%$ patients after 6 months of the following laparoscopic ovarian drilling. Ovulation and pregnancy were significantly higher after 6 months following laparoscopic ovarian drilling.

\section{DISCUSSION}

A total 66 infertile patients having $\mathrm{CC}$ resistant PCOS (failure to ovulate in response to $\mathrm{CC}$ in three consecutive cycles with dose of $150 \mathrm{mg}$ daily for 5 days from day 2 of menstrual cycle) were recruited in this study. Amongst them, 6 patients were dropped out during follow up. Finally, 60 cases were included in this study. This interventional study was carried out in the department of obstetrics and gynecology, Bangabandhu Sheikh Mujib medical university, Dhaka from July 2014 to June 2015. In this study, a complete history and clinical examination (including menstrual abnormalities, acne, BMI), biochemical parameters (including basal level of day 2 serum FSH, LH, serum testosterone, OGTT and fasting serum insulin level were done before LOD. And to identify the changes in clinical and biochemical profile and the ovulation and pregnancy rate following LOD in CC resistant PCOS patients. In this study, it was observed that the mean age was found to be $26.8 \pm 3.6$ years varied from 20-34 years. Jahan et al and Jonard et al found that the mean age was $25.68 \pm 3.81$ years varied from 18 to 35 years and $27.2 \pm 4.7$ years varied from 31 to 34 years respectively, which resembled closely with the present study. ${ }^{11,12}$ On the other hand, Leustean et al and Ehrmann et al has observed higher mean age of the patients having PCOS, which were $31.28 \pm 6.0$ years and $29.2 \pm 0.5$ years respectively. ${ }^{13,14}$ Similarly, Amer et al showed that the mean age was 33.3 \pm 4.4 years which is also higher with the current study. ${ }^{7}$ In another study, Begum showed the mean age was $22.67 \pm 6.3$ years varied from 18 to 35 years and Codner et al found mean age was $24.5 \pm 5.0$ years varied from 19 to 40 years which are less than the current study. ${ }^{15}$ Summed ovarian volume $\left(\mathrm{cm}^{3}\right)$ were found between responders and non-responders after LOD. A systematic review Badawy et al and Elmashad concluded that ovarian volume has little clinical application in prediction of poor pregnancy response. ${ }^{16,17}$ However, another recent review commented on the value of ovarian volume with regard to its easy execution, and therefore could be included in preparatory protocols providing data for continuity of research. ${ }^{1}$ In this current study it was observed that regular menstruation was found $16.7 \%$ in before LOD and $58.3 \%$ in after 6 months following LOD. Menstrual history was statistically significant $(\mathrm{p}<0.05)$ as compared with before LOD and after 6 months following LOD. In Seyam et al study, among 40 PCOS women having LOD, $75.0 \%$ had regular cycles in the 6-month period after LOD. ${ }^{18}$ Many authors observed that LOD restored menstrual regularity in a significant proportion $(63-86.0 \%)$ of women..$^{9,14,19,20}$ In the current study, it was observed that acne was found in $36.7 \%$ patients before LOD and in $21.7 \%$ patients after 6 month following LOD, which was statistically significant $(p<0.05)$ compare with before LOD and after 6 months LOD. In another study that 16 out of 29 patients who claimed their acne improvement in their symptoms after LOD while one said that it got worse. In this study, it was observed that BMI $\left(>25 \mathrm{~kg} / \mathrm{m}^{2}\right)$ was found in $71.7 \%$ in before LOD and was found in $50.0 \%$ after 6 months following LOD, which was statistically significant $(p<0.05)$ compare with before LOD and after 6 months LOD.

it was observed that mean luteinizing hormone level was found in $17.6 \pm 4.6 \mathrm{miu} / \mathrm{ml}$ before LOD and in 9.0 \pm 0.6 $\mathrm{miu} / \mathrm{ml}$ after 6 month following LOD. Mean testosterone was found in $31.1 \pm 12.7 \mathrm{ngm} / \mathrm{ml}$ before LOD and 16.6 \pm 0.8 $\mathrm{ngm} / \mathrm{ml}$ after 6 month following LOD. Mean fasting insulin was found 21.9 \pm 4.3 Mean LH level was found in $17.6 \pm 4.6 \mathrm{miu} / \mathrm{ml}$ in before LOD and was found in 9.0 \pm 0.6 $\mathrm{miu} / \mathrm{ml}$ after 6 month following LOD. Mean testosterone was found in $31.1 \pm 12.7 \mathrm{ngm} / \mathrm{dl}$ patients before LOD and was found in $16.6 \pm 0.8 \mathrm{ngm} / \mathrm{dl}$ after 6 month following LOD. The changes of the serum levels of FSH after LOD were variable and insignificant in groups $1-5(-10$ to $+9 \%)$, but there was a significant increase of $29.0 \%$ in group 6 . Seyam et al study confirmed nosignificant changes in the serum concentration of FSH throughout the follow-up periods after. ${ }^{21} \mathrm{FSH}$ concentrations increased shortly after LOD, and then gradually returned to baseline values but without significant changes. In addition, no significant differences in FSH levels were found between pre and post LOD either in responders or non-responders. Estradiol levels (E2) increased slightly during the first week after LOD and then increased at 3 and 6 months of follow-up but without statistical significance, without a significant difference in E2 levels between pre and post LOD either responders or non-responders. Also, the serum levels of LH and the LH: FSH ratio decreased significantly 1-week after LOD and remained low during the 3-and 6-month follow-up periods. The reduction of androgens and $\mathrm{LH}$ levels after LOD has been reported by other investigators. In another study Amer et al obtained that pre-treatment LH levels did not seem to influence the ovulation rates of LOD. ${ }^{12}$ However, once ovulation is achieved, LH levels appear to have a significant impact on pregnancy rate. LOD responders with higher LH levels ( $\geq 10$ IU/1) have a significantly higher chance of conception than those with over LH levels. In this series, it was observed that ovulation was found $25.0 \%$ in after 3-month LOD and $70.0 \%$ in after 6 months following LOD. Pregnancy was found in $20.0 \%$ after 3-months LOD and $50.0 \%$ after 6 
months following LOD. However, 20-30\% of anovulatory PCOS women failed torespond to LOD. Therefore, it is not exactly clear why some PCOS patient do not respond to treatment with LOD. In another study Radwan et al obtained that patient after laparoscopy ovulation occurred in $84.0 \%$ and pregnancy in $53.0 \% .^{23}$

It was observed that ovulation was found in $25.0 \%$ and $70.0 \%$ patients after 3 month and 6 months respectively following LOD. Ovulation rate was statistically significant $(p<0.05)$ after 6 months following LOD. Pregnancy was found in $20.0 \%$ patients after 3 months following LOD and was found in $50.0 \%$ patients after 6 months following LOD. Ovulation and pregnancy were significantly higher after 6 months following LOD.

\section{Limitations}

This was a single centre study with small sample size. So, the results may not be reflected in the whole country.

\section{CONCLUSION}

This study was undertaken to identify the changes in clinical and biochemical profile and the ovulation and pregnancy rate following LOD in $\mathrm{CC}$ resistant PCOS patients. patients. Age group between 25-30 years. Clinical parameters (Menstrual history, Acne, and BMI status), and biochemical parameters (Luteinizing hormone, testosterone, fasting insulin and OGTT status) were significantly $(\mathrm{p}<0.05)$ improved after 6 months following LOD. TVS findings (ovarian volume, follicular size, endometrial thickness) were significantly $(\mathrm{p}<0.05)$ improved after 6 months following LOD. Ovulation and pregnancy were found in $70 \%$ and $50.0 \%$ respectively after 6 months following LOD which were significantly $(\mathrm{p}<0.05)$ improved.

\section{Funding: No funding sources}

Conflict of interest: None declared

Ethical approval: The study was approved by the Institutional Ethics Committee

\section{REFERENCES}

1. Asuncion M, Calvo RM, San Millan JL, Sancho J, Avila S, Escobar-Morreale HF. A prospective study of the prevalence of the polycystic ovarian syndrome in unselected Caucasian women from Spain. J Clin Endocrinol Metab. 2000;85:2434-8.

2. Hull MG. Epidemiology of infertility and polycystic ovarian disease: endocrinological and demographic studies. Gynecol Endocrinol. 1987;1:235-45.

3. Balen AH, Laven JS, Tan SL, Dewailly D. Ultrasound assessment of the polycystic ovary: international consensus definitions. Hum Reprod Update. 2003;9(6):505-14.

4. Rotterdam ESHRE/ASRM-Sponsored PCOS Consensus Workshop Group. Revised 2003 Consensus on diagnostic criteria and long-term health risks related to polycystic ovary syndrome. Fertil Steril. 2004;81:19-25.

5. Radwan J, Bielak A, Banaszczsk R, Pawlicki J. The effects of micro-laparoscopic ovarian electrocautery as a method of polycystic ovary syndrome treatment. Ginekol Pol. 2001;72(8):642-6.

6. Liguori G, Tolino A, Mocciia G, Scongnamiglio G, Nappi C. Laparoscopic ovarian treatment in infertile patients with polycystic ovary syndrome: endocrine changes and clinical outcome. Gynecol Endocrinol. 1996;10(4):257-64.

7. Amer SAK, Gopalan V, Li TC, Ledger WL, Cooke ID. Long term follow up of patients with polycystic ovarian syndrome after laparoscopic ovarian drilling: clinical outcome. Hum Reprod. 2002;17:2035-2042.

8. Lemieux S, Lewis GF, Ben-Chetrit A, Steiner G, Greenblatt EM. Correction of hyperandrogenemia by laparoscopic ovarian cautery in women with polycystic ovary syndrome is not accompanied by improved insulin sensitivity or lipid lipoprotein levels. J Clin Endocrinol Metab. 1999;84(11):4278-82.

9. Felemban A, Tan SL, Tulandi T. Laparoscopic treatment of with insulated needle cautery: a reappraisal. Fertil Steril. 2000;73:266-9.

10. Tulandi T, Watkin K, Tan SL. Reproductive performance and three-dimensional USG volume measurements of polycystic ovary syndrome following laparoscopic ovarian drilling. Int J Fertil Womens med. 1997;42:436-40.

11. Abdel-Gadir A, Mowafi RS, Alnaser HMI, Alrashid $\mathrm{AH}$, Alonezi OM, Shaw RW. Laparoscopic ovarian drilling versus Recombinant FSH therapy in the treatment of patients with polycystic ovarian syndrome. Clin Endocrinol. 1990;33:585-92.

12. Amer SAK, Li TC, Cooke ID. Laparoscopic ovarian diathermy in women with polycystic ovarian syndrome: a retrospective study on the influence of the amount of energy used on the outcome. Hum Reprod. 2002;17(4):1046-51.

13. Amer SAK, Li TC, Ledger WL. Ovulation induction using Laparoscopic ovarian drilling in women with polycystic ovarian syndrome: predictors of success. Hum Reprod. 2004;19:1719-24.

14. Li TC, Saravelos H, Chow MS, Chisabingo R, Cooke ID. Factors affecting outcome of laparoscopic ovarian drilling for polycystic ovarian syndrome in women with anovulatory infertility. $\mathrm{Br} \mathrm{J}$ Obstet Gynecol. 1998;105:338-44.

15. De Frene V, Gerris J, Weyers S, Dhont M, Vansteelandt S, Annemans L et al. Gonadotropin Therapy versus Laparoscopic Ovarian Drilling in Clomiphene Citrate-Resistant Polycystic Ovary Syndrome Patients: A Retrospective CostEffectiveness Analysis. Gynecol Obstet Invest. 2015;80(3):164-9.

16. Brown J, Farquhar C, Beck J, Boothroyd C, Hughes E. Clomiphene and anti-estrogens for ovulation induction in PCOS. Cochrane Database Systematic Reviews. 2009;4:CD002249. 
17. National Collaborating Centre for Women's and Children's Health / National Institute for Clinical Excellence. Fertility: assessment and treatment for people with fertility problems. Clinical Guideline London. UK. 2004;11.

18. Imani B, Eijkemans MJC, Velde ER, Habbema JD, Fauser BC. Predictors of patients remaining anovulatory during clomiphene citrate induction of ovulation in normo-gonadotropic oligomenorrheic infertility. J Clin Endocrinol Metab. 1998;83(7):23615.

19. Parsanezhad ME, Alborzi S, Zarei A, Dehbashi S, Omrani G. Insulin resistance in clomiphene responders and nonresponders with polycystic ovarian disease and therapeutic effects of metformin. Int $\mathbf{J}$ Gynecol Obstetr. 2001;75(1):43-50.

20. Overbeek A, Kuijper EA, Hendriks ML, Blankenstein MA, Ketel IJ, Twisk JW et al. Clomiphene citrate resistance in relation to follicle-stimulating hormone receptor Ser680Ser-polymorphism in polycystic ovary syndrome. Human Reproduction. 2009;24(8):2007-13.
21. Mwan MD. Evaluation of compound optimality criteria for second order rotatable designs constructed using balanced incomplete block design (Doctoral dissertation, MOI university). 2017.

22. Shahrokhi M, Khorasani SK, Ebrahimi A. Study of genetic components in various maize (Zea mays L.) traits, using generation mean analysis method. Int $\mathrm{J}$ Agronomy Plant Product. 2013;4(3):405-12.

23. Radwan OK, Shehata AM. Comparison of the therapeutic actions of taurine, methyl sulfonyl methane and silymarin against acetaminopheninduced neuro-and hepato-toxicity in adult male albino rats. J biomed pharmaceutical res. 2016;5(3):10-7.

Cite this article as: Banu J, Ishrat S, Deeba F, Alamgir CF, Darmoni M, Begum N et al.

Laparoscopic ovarian drilling in clomiphene resistant polycystic ovarian syndrome: clinical response and outcome. Int J Reprod Contracept Obstet Gynecol 2021;10:3684-90. 